\title{
Functional results of osteosynthesis with mini-plate and screws in metacarpal shaft fractures
}

Faisal Hassan Zayed ${ }^{1}$ MD, Mohammed Salah Abd-Elhafez ${ }^{1}$ MD, and Hossam Hassan Abdelhady ${ }^{1}$ MBBCh

\author{
Disclosure: The authors have no \\ financial interest to declare in relation \\ to the content of this article. The Article \\ Processing Charge was paid for by the \\ authors. \\ Authorship: All authors have a \\ substantial contribution to the article. \\ *Corresponding Author: \\ Hossam Hassan Abdelhady \\ hossamhassan141196@gmail.com
}

Received for publication May 2 , 2020; Accepted June 28, 2020; Published online June 29, 2020.

Copyright 2020 The Authors published by Al-Azhar University, Faculty of Medicine, Cairo, Egypt. All rights reserved. This an openaccess article distributed under the legal terms, where it is permissible to download and share the work provided it is properly cited. The work cannot be changed in anyway or used commercially.

\section{doi:10.21608/aimj.2020.30159.1226}

${ }^{1}$ Orthopedic Surgery Department, Faculty of Medicine, Al-Azhar University.

\begin{abstract}
Introduction: Metacarpal fractures are usually managed by conservative methods, but using these conservative methods in unstable fractures usually show poor results. Surgical intervention is recommended in this fracture types.This study aims to assess the functional outcomes of plate fixation in metacarpal shaft fractures. The assessment was done by using the Total Active Flexion score according to the American Society for Surgery of the Hand.

Patients \& Methods: This is a prospective study that was conducted at Al-Hussein University Hospital in a period between April 2017 and November 2019. This study included a total of 20 patients diagnosed with displaced, irreducible, and unstable metacarpal shaft fractures. Miniplate and screws were used for the fracture fixation. The patient's age varied from 20 to 50 years old.

Results: This study included 20 patients, 10 patients were males (50\%) and 10 were females (50\%). The dominant hand was involved in 14 patients (70\%). Fracture union was completed in all patients between 8-12 weeks with an average of 10 weeks. The total active flexion was measured and showed excellent scores in 14 patients, good scores in 4 patients, and fair scores only in 2 patients.

Conclusion: Mini-plate and screws is a good choice for unstable metacarpal fracture fixation. The use of mini-plate and screws provide rigid stable fixation which allows early hand movement and achieving good functional outcomes.
\end{abstract}

Keywords: Metacarpal fracture; Mini-plate and screws; total active flexion score.

\section{INTRODUCTION}

Metacarpal fractures represent about $30 \%$ of fractures of the hand. Metacarpal fractures usually caused by axial loading, twisting injury, or direct trauma. ${ }^{1}$

The goals of the treatment are anatomic reduction of the fracture, length restoration, rotational deformity correction, adequate fixation, proper handling of soft tissues, and early movement of the hand. ${ }^{2}$

Metacarpal fractures are usually treated conservatively, but unstable, irreducible, and displaced fractures treated with conservative methods usually show poor outcomes. Surgical treatment is recommended in these fractures. ${ }^{3}$

There are different surgical techniques, but plate fixation provides a rigid stability which allows bone union and early active hand motion which is significant for surgical treatment outcomes. ${ }^{4}$

\section{MATERIAL AND METHODS}

This study included 20 patients diagnosed with unstable metacarpal fractures who were operated at Al-Hussein University Hospital in a period between April 2017 and November 2019. Mini-plate fixation was used for these fractures.The study was approved by the ethical committee of Al-Azhar Faculty of Medicine and written consent was obtained from all patients before any surgical intervention.

Patients were included in this study if they aged between 20 and 50 years old and diagnosed with closed, displaced, rotated, and angulated metacarpal fractures. Patients were excluded if they have had intraarticular fractures, open fractures, thumb fractures, metacarpal neck fractures, or ipsilateral upper extremity fractures.

Surgical technique: All surgical interventions were performed while the patient in a supine position with the hand supported on a table, and a 
tourniquet was applied over the arm.A dorsal approach was used through incision of skin and subcutaneous tissues to expose extensor tendons and dorsal interossei muscles.(Figure1)

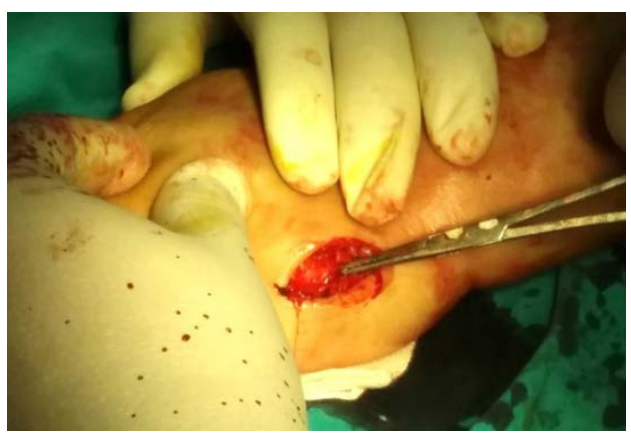

Fig. 1: Superficial dissection to expose the extensor tendons.

The extensor tendons were retracted gently to expose metacarpal shaft, then the fracture site was exposed by periosteal elevator.(Figure 2)

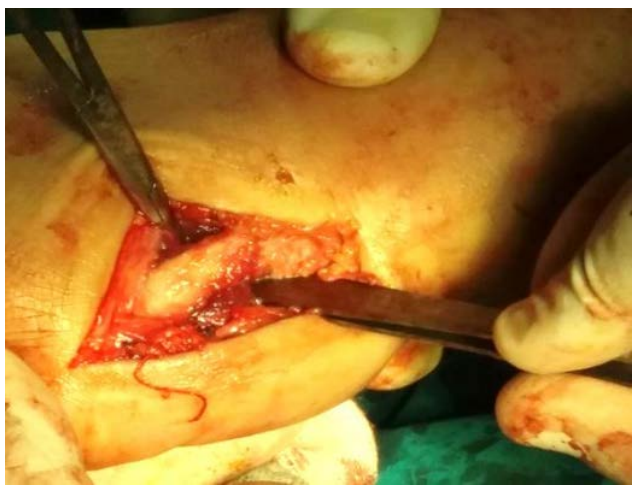

Fig. 2: Deep dissection to expose the metacarpalshaft.

After irrigating the fracture hematoma and removing any interposed tissue in the fracture site, the reduction was performed using longitudinal traction on the finger. Blunt reduction forceps were used to grasp and reduce both fragments of fracture anatomically. A reduction towel was used to hold the reduction, and fracture fixation was done by using mini-plate and screws.(Figure3)

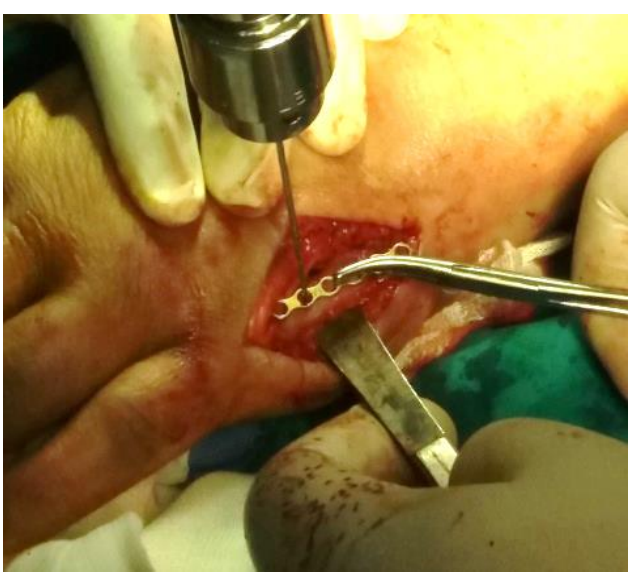

Fig. 3:Plate fixation.
In oblique or spiral fractures, an interfragmentary lag screw $(2.0 \mathrm{~mm})$ was used to obtain initial fixation. A countersink was used to reduce the prominence of the screw head. Rotational alignment of the involved digit was confirmed by observing any overlapping or divergence of digits.

Final AP and lateral fluoroscopic views were taken to evaluate the plate position and confirm that there was no displacement at the fracture site. The wound was irrigated and hemostasis was ensured, then the plate was covered by soft tissue to avoid tendon irritation. Finally, closure of the wound was done by simple sutures

\section{Post-operative protocol:}

A dorsal below elbow slab was placed with the wrist and the hand immobilized in the position of safety. Fracture healing was monitored both clinically and radiographically. Early controlled active ROM out of the splint was started at the first follow up visit (2 weeks after operation).

The patient's functional outcomes were assessed by using TAF (Total Active Flexion) score at each follow-up visit (table 1).

Total active Flexion is measured by summation of the flexion degrees of the distal interphalangeal (DIP), proximal interphalangeal (PIP), and metacarpophalangeal (MCP) joints then subtracting the sum of the extension deficits at each joint. This value can then be compared with that of the contralateral hand or a normal value to provide a more accurate assessment of each digit. ${ }^{5}$

\begin{tabular}{|l|l|}
\hline Degree of flexion & Results \\
\hline $220^{\circ}-260^{\circ}$ & Excellent \\
\hline $180^{\circ}-219^{\circ}$ & Good \\
\hline $130^{\circ}-179^{\circ}$ & Fair \\
\hline Less than $130^{\circ}$ & Poor \\
\hline
\end{tabular}

Table1: TAF Score System from MCPJ to DIPJ (digits 2-5).

\section{RESULTS}

This was a prospective study for evaluation of miniplate and screws fixation in the treatment of unstable metacarpal fractures and included 20 patients. The patient's age ranged from 20 to 50 years with a mean age of 35 years. 10 patients in the study were males (50\%) and 10 were females (50\%).

The selected cases were followed up for at least six months. Union of fractures was seen in all patients (100\%) ranging between 8-12 weeks with an average of 10 weeks. (Figure 4)

The fracture patterns were transverse in 8 patients, spiral in 4 patients, and oblique in 8 patients.

We used the TAF score to evaluate the patient's functional results. The score was $260^{\circ}$ in 2 patients, $250^{\circ}$ in 10 patients, $240^{\circ}$ in 2 patients, $210^{\circ}$ in 2 
patients, $200^{\circ}$ in 2 patients, $170^{\circ}$ in 1 patient, and $150^{\circ}$ in 1 patient.

The results of the current study after six months follow up was as follow:

- Excellent scores in fourteen patients (70\%) (Figure 5)

- Good scores in four patients (20\%)

- Fair scores in two patients (10\%)
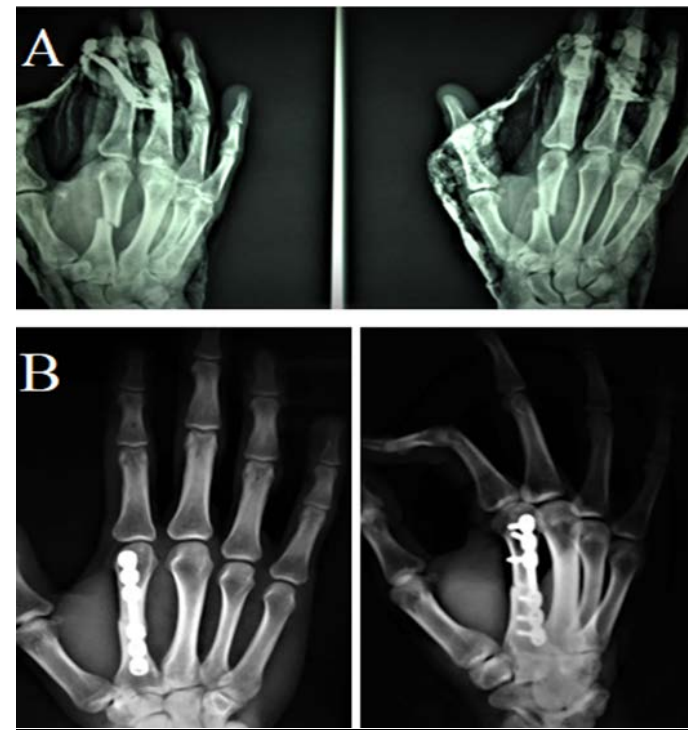

Fig. 4: (A) preoperative radiographic image. (B) full union of 2nd metacarpal of Rt. Hand at 12 weeks postoperative.

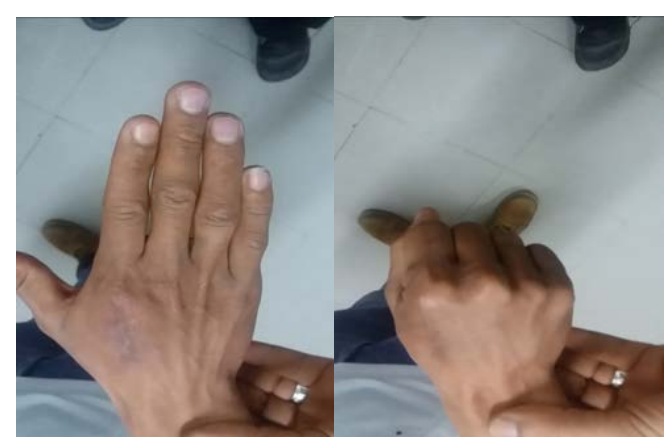

Fig. 5: The patient showed full ROM and his TAF score was $260^{\circ}$ (excellent)

One patient had stiffness of metacarpophalangeal and interphalangeal joints. The patient was put on a strict physiotherapy regimen but he neglected regular follow up, and his total active flexion score was $150^{\circ}$ (fair). One patient had wound complication (keloid) without any affection on hand functions.

No patient in the study developed tendon irritation. There were no cases of rotational or angular displacement.

\section{DISCUSSION}

Stable metacarpal fractures usually managed successfully by conservative methods, but unstable fractures require surgical intervention as the closed treatment of these fractures showed unsatisfactory results. ${ }^{6}$

This study evaluated the management of unstable metacarpal fractures by mini-plate fixation. The functional results were assessed by using the TAF (Total Active Flexion) score.

This study included a total of 20 patients that was a relatively accepted number in comparison to the other studies. Souer et al. ${ }^{7}$ reported 18 patients, Gupta et al. ${ }^{8}$ reported 31 patients, Trevisan et al. ${ }^{9}$ reported 42 patients in their studies, and Ashwani et al. ${ }^{10}$ reported the results of treating 21 patients.

The patient's age ranged from 20 to 50 years with a mean age 35 years, similar to the mean age at souer et al. ${ }^{7}$ study that was 34 years (18-50), but lower than the mean age in the studies made by Trevisan $\mathrm{C}$ et al. ${ }^{9}$ with the mean age was 39.4 (17-77 years), and Ashwani et al. ${ }^{10}$ with the mean age was 49.5 (16-75 years).

In this study, the dominant hand was involved in 14 patients (70\%), twelve patients had 1 metacarpal fracture and eight patients had 2 metacarpal fractures. Trevisan $\mathrm{C}$ et al. ${ }^{9}$ included the dominant hand in 31 patients and reported that thirty-four patients had 1 , six patients had 2, and two patients had 3 metacarpal fractures. Ashwani et al. ${ }^{10}$ reported that eleven patients had 2, seven patients had 3, and three patients had 4 metacarpal fractures.

The dorsal approach to metacarpals was used in all cases. This approach provided good access to the metacarpals and still the recommended approach by many trauma surgeons. Good surgical technique, proper handling of soft tissues, extensor tendons, and vascularity preservation has been shown to produce good functional results.

In this study, the bone union was seen in all cases $(100 \%)$, unlike other studies. Souer et al. ${ }^{7}$ reported that only one patient showed a delayed union. Page and Stern ${ }^{12}$ reported nonunion in one of sixty-six patients, and Stern et al. ${ }^{13}$ found nonunion in three of seventeen patients.

The TAF was measured and showed excellent scores in 14 patients, good scores in 2 patients, and fair scores only in 2 patients. The overall results were satisfactory.

Some authors used the same score to assess their results. In the study made by Trevisan $\mathrm{C}$ et al. ${ }^{9}$, the average TAF of their cases was $256^{\circ}$ (range $175^{\circ}$ $260^{\circ}$ ). Bosscha K et al. ${ }^{11}$ reported that the TAF score was excellent in 31 of 34 patients (92\%) and poor in 3 of 34 patients (8\%).

Ashwani et al. ${ }^{10}$ used the TAF score and DASH (disability of hand, shoulder, and arm) score. TAF score was poor only in 1 patient and excellent in the 
remaining patients. The mean DASH score was 8.47 (range 1-26).

In our study, one patient had a keloid without any affection on hand functions and another patient had finger stiffness because he missed the follow-up visits and neglected the physiotherapy exercises.

Low complication rate in the current study was similar to the results reported by Dabezies and Schutte in their study on 27 cases diagnosed with metacarpal fractures and treated by using plate fixation. ${ }^{14}$ Fusetti $C$ et al. reported that open hand fractures with massive soft tissue injury have high complication rates. ${ }^{15}$

Several studies have been established to compare the relative strength of different techniques of metacarpal fracture fixation.

James et al. reported that using closed methods in the treatment of unstable fractures had led to a loss of function in $77 \%$ of fingers. ${ }^{16}$

One of the treatment methods in these unstable fractures is open reduction and $\mathrm{K}$ wire fixation, but they provide less stable fixation, there is a risk of infection and significant problems caused by the wire protruding ends. ${ }^{17}$

An external fixator can be used for the metacarpal fracture fixation. A study of Shehadi et al. reported that $100 \%$ of their patients diagnosed with metacarpal fractures and treated by using the external fixator showed full return of hand motion. This type of fixation is recommended especially in open fractures with bone loss. The disadvantages of using the external fixators are pin tract infection, construct loosening and loss of fixation. ${ }^{18}$

Orbay et al. reported that using intramedullary wiring of metacarpal fractures with k-wires is one of the treatment methods used for short oblique and transverse fractures. They provide good functional results, but there is an incidence of reduction loss and hardware penetration of metacarpophalangeal joint which requires a second surgery for hardware removal. ${ }^{19}$

Several advantages have been outlined in the current study, as the plate osteosynthesis for metacarpal fractures provides anatomical reduction and rigid fixation which allows early hand movement without reduction loss thus decreasing the possibility of stiffness and provides good functional outcomes. Plate fixation corrects the shortening of metacarpal fractures and restores the strength of interossei muscle, thereby maintaining the grip strength of the hand.

The possible limitations in our study were short follow up period (6 months), and a relatively small number of the patients.

\section{CONCLUSION}

Mini-plate and screws is a good choice for unstable metacarpal fracture fixation. The use of mini-plate and screws provide rigid stable fixation allowing early hand movement and achieving good functional outcomes.

\section{REFERENCES}

1. Diaz-Garcia R, Waljee JF. Current management of metacarpal fractures. Hand Clin. 2013: 29, 507-18.

2. Rhee PC, Becker HA, Rizzo M. Update on the Treatment of Metacarpal Fractures. Cur OrthopPract. 2012: 23, 289-95

3. Stern PJ. Fractures of the metacarpals and phalanges. In: Green DP, Hotchkiss RN, Pederson WC, Wolfe SW, editors. Green's operative hand surgery. Vol 1. 5th ed. Philadelphia: Elsevier Churchill Livingstone. 2005: p. 286-294.

4. Carpenter S, Rohde RS. Treatment of phalangeal fractures. Hand Clin. 2013: 29, 519534 .

5. Jodi 1. Seftchick. Clinical examination of the hand. InTerri M. Skirven,A. Lee Osterman, Jane Fedorczyk, Peter C. Amadio, editors. Rehabilitation of the hand and upper extremity. Vol 1. 6th ed. Elsevier. 2011: p.58.

6. Amadio PC. Fractures of the hand and the wrist. In: Jupiter JB, editor. Flynn's hand surgery. Williams \& Wilkins, Baltimore. 1991: 122-185.

7. Souer JS, Mudgal CS. Plate fixation in closed ipsilateral multiple metacarpal fractures. $J$ Hand Surg Eur. 2008: 33, 740-4.

8. Gupta R, Singh R, Siwach RC, et al. Evaluation of surgical stabilization of metacarpal and phalangeal fractures of hand. Indian $J$ Orthopaedics. 2007:41, 224-229.

9. Trevisan C, Morganti A, Casiraghi A. Low severity metacarpal and phalangeal fractures treated with miniature plates and screws. Arch Orthop Trauma Surg. 2004: 124, 675-80.

10. Ashwani Soni, Anmol Gulati, J.L Basi. Outcome of closed ipsilateral metacarpal fractures treated with minifragment plates and screws. $J$ Journal of Orthopedics and Traumatology. 2012: 13, 29-33.

11. Bosscha K, Snellen JP. Internal fixation of metacarpal and phalangeal fractures with $\mathrm{AO}$ minifragment screws and plates: A prospective study. Injury. 1993: 24, 166-8.

12. Page SM, Stern PJ. Complications and range of motion following plate fixation of metacarpal and phalangeal fractures. J Hand Surgery. 1998: 23, 827-832 . 
13. Stern PJ, Wieser MJ, Reilly DG. Complications of plate fixation in the hand skeleton. ClinOrthopRelat Res. 1987: 214, 59-65 .

14. Dabezies EJ, Schutte JP. Fixation of metacarpal and phalangeal fractures with miniature plates and screws. J Hand Surgery. 1986: 11, 283288.

15. Fusetti C, Meyer $\mathrm{H}$, Borisch $\mathrm{N}$, et al. Complications of plate fixation in metacarpal fractures. J Trauma. 2002: 52, 535-539.

16. James JI. Fractures of the proximal and middle phalanges of the fingers. Acta Orthop Scand. 1962: 32, 401-12.
17. Orbay JL, Indriago I, Gonzalez E. Percutaneous fixation of metacarpal fractures. Op Tech Plast Reconstruct Surg. 2002: 9,138-142.

18. Shehadi SI. External fixation of metacarpal and phalangeal fractures. $J$ Hand Surg. 1991: 16, 544-50 .

19. Orbay J. Intramedullary nailing of metacarpal shaft fractures. Tech Hand up Extrem Surg. 2005: 9, 69-73. 